\title{
Monophasic action potential recordings during acute changes in ventricular loading induced by the Valsalva manoeuvre
}

Peter Taggart, Peter Sutton, Roy John, Max Lab, Howard Swanton

\begin{abstract}
Objective-The strong association between ventricular arrhythmia and ventricular dysfunction is unexplained. This study was designed to investigate a mechanism by which a change in ventricular loading could alter the time course of repolarisation and hence refractoriness. A possible mechanism may be a direct effect of an altered pattern of contraction on ventricular repolarisation and hence refractoriness. This relation has been termed contractionexcitation feedback or mechano-electric feedback.
\end{abstract}

Methods-Monophasic action potentials were recorded from the left ventricular endocardium as a measure of the time course of local repolarisation. The Valsalva manoeuvre was used to change ventricular loading by increasing the intrathoracic pressure and impeding venous return, and hence reducing ventricular pressure and volume (ventricular unloading)

Patients-23 patients undergoing routine cardiac catheterisation procedures: seven with no angiographic evidence of abnormal wall motion or history of myocardial infarction (normal), five with a history of myocardial infarction but with normal wall motion, and 10 with angiographic evidence of abnormal wall motion-with or without previous infarction. One patient was a transplant recipient and was analysed separately.

Setting-Tertiary referral centre for cardiology.

Results-In patients with normal ventricles during the unloading phase of the Valsalva manoeuvre (mean (SD)) monophasic action potential duration shortened from 311 (47) ms to 295 (47) ms $(p<0.001)$. After release of the forced expiration as venous return was restored the monophasic action potential duration lengthened from 285 (44) $\mathrm{ms}$ to 304 (44) ms $(p<0.0001)$. In the group with evidence of abnormal wall motion the direction of change of action potential duration during the strain phase was normal in $7 / 21$ observations, abnormal in $6 / 21$, and showed no clear change in $8 / 21$. During the release phase $11 / 20$ observations were normal, five abnormal, and four showed no clear change. In those with myocardial infarction four out of five patients had changes that resembled those with normal ventricles but the changes were less pronounced. There were no differences in any of the three groups between the changes in monophasic action potential duration in patients taking $\beta$ blockers and those who were not. The changes in monophasic action potential duration in the transplanted heart resembled those in the group with normal ventricles. Inflections on the repolarisation phase of the monophasic action potential consistent with early afterdepolarisations were seen in three of the patients with abnormal wall motion and in none of those with normal wall motion.

Conclusions-These results are further evidence that changes in ventricular loading influence repolarisation. When wall motion was abnormal the effects on regional endocardial repolarisation were often opposite in direction to those when it was normal. Thus regional differences in wall motion could generate local electrophysiological inhomogeneity which may be relevant to the association of arrhythmia with impaired left ventricular function.

There is a strong association between sudden cardiac death and abnormal ventricular wall motion in patients with coronary artery disease. $^{12}$ The severity of impairment of left ventricular function is a major predictor of mortality after myocardial infarction ${ }^{34}$ and patients developing an aneurysm within 48 hours are at particular risk. ${ }^{5}$ Death is generally considered to be due to arrhythmia and there is a strong correlation in these patients between abnormal wall motion and ventricular arrhythmia. ${ }^{6-8}$ Patients with volume or pressure overload such as aortic valve disease ${ }^{2-11}$ or dilated cardiomyopathy ${ }^{12}$ commonly have ventricular arrhythmia. Though in some patients with congestive cardiac failure death is due to electromechanical uncoupling, sudden death in these patients is also partly due to the increased incidence of ventricular arrhythmias. ${ }^{13-15}$ The explanation for the association between abnormality of 
ventricular wall motion and serious arrhythmia, however, is unclear.

One possible mechanism may be a direct effect of ventricular loading on the time course of repolarisation and hence refractoriness. This mechanism is known as contractionexcitation feedback $^{16}$ (or mechano-electric feedback).

A change in the normal time sequence of repolarisation alters local electrical gradients and is potentially arrhythmogenic. ${ }^{17}$ It is known that areas of myocardium where wal motion is abnormal contract differently from normal areas. ${ }^{1819}$ It would be expected therefore that the effect on repolarisation time in abnormally contracting and normally contracting areas of myocardium would be different. In the presence of abnormal wall motion local electrical gradients may be generated which might play a part in the initiation of arrhythmias in these circumstances.

Several studies have examined contractionexcitation feedback in some detail and such feedback has been shown in isolated tissues, ${ }^{20}$ isolated hearts, ${ }^{21-23}$ and whole animals. ${ }^{212425}$ In general these studies have shown that increasing myocardial stretch/strain or increasing loading conditions result in shortening of action potential duration (ie repolarisation time) $)^{1621}$ altered refractoriness ${ }^{22242627}$ and arrhythmia formation. ${ }^{232528} 29$ Until recently ${ }^{30-32}$ there has been no evidence for the existence of this phenomenon in humans. In the present study we used the Valsalva manoeuvre to change ventricular loading within the physiological range in patients undergoing routine cardiac catheterisation for chest pain. ${ }^{33-35}$ We recorded monophasic action potentials from the left ventricular endocardium as a measure of repolarisation ${ }^{36}{ }^{37}$ in patients with angiographic evidence of wall motion abnormality and in those without.

The aims of this study were (a) to see whether pressure/volume changes influence the timing of regional ventricular endocardial repolarisation and to seek evidence that changes in ventricular loading influence the timing of repolarisation; $(b)$ to see whether patients with abnormal wall motion and those with normal wall motion respond differently; (c) to see whether there are any electrophysiological changes that would be in keeping with those required for arrhythmia generation.

\section{Patients and methods}

We recorded the left ventricular monophasic action potential, arterial pressure, and the routine electrocardiogram in patients undergoing routine cardiac catheterisation for chest pain or, in one patient, routine left ventricular biopsy after heart transplantation.

\section{PATIENTS}

Twenty three patients (table 1) were selected at random from the waiting list including one (patient 23) admitted for routine biopsy after a heart transplant. The patients were divided into three groups:
Group 1-Those with no demonstrable angiographic abnormality-that is, normal $(\mathrm{n}=7)$.

Group 2-Those with normal wall motion but a history of myocardial infarction and therefore possible abnormality of left ventricular wall motion not detectable by the methods used in this study $(n=5)$.

Group 3-Those with angiographic evidence of abnormal left ventricular wall motion either with or without previous history of myocardial infarction $(n=10)$.

The transplant patient was analysed separately. The study was approved by the hospital ethics committee and informed consent obtained.

METHOD OF EVALUATION OF LEFT VENTRICULAR WALL MOTION FROM LEFT VENTRICULAR CINEANGIOGRAMS

Ventricular synergy was assessed by single plane left ventriculography in the $30^{\circ}$ right anterior oblique projection. ${ }^{38} 39$ A long axis of the left ventricular endocardial silhouette was drawn between the midpoint of the aortic valve and the left ventricular apex for both end diastolic and end systolic frames. The long axes of the two frames were ther aligned and the silhouettes superimposed at the midpoint of the long axis. The long axis was further subdivided to give six segments: anteroapical, inferoapical, anteromedial, inferomedial, anterobasal, and inferobasal. The systolic change in length for each of the above reference segments was normalised for end diastolic length and expressed as percentage shortening (or lengthening in the case of dyskinesis). The inferobasal segment was excluded from analysis of regional contractility because of its large individual variability. ${ }^{40}$

ENDOCARDIAL MONOPHASIC ACTION POTENTIALS Left ventricular monophasic action potentials were recorded by a purpose built (Cordis) bipolar pressure contact silver/silver chloride catheter electrode (size 7 French). The contact electrode was positioned at the tip with the indifferent electrode $5 \mathrm{~mm}$ proximally, flush with the side wall of the catheter. Gentle pressure of the tip electrode against the endocardium gave a signal of between 20 and $40 \mathrm{mV}$.

\section{ARTERIAL PRESSURE}

The routine arterial pressure signal obtained via the catheter sheath was recorded on a Gould Instruments electrostatic chart recorder (model ES1000) at a paper speed of $10 \mathrm{~mm} / \mathrm{s}$ and used for systolic pressure measurement.

\section{SIGNAL PROCESSING}

The monophasic action potential signals were fed into a Gould isolated preamplifier (model 11-5407-58) and then into a DC Gould universal amplifier (model 13-4615-58). The amplifier was set to give an output of $1 \mathrm{~V}$ for $40 \mathrm{mV}$ input with a frequency response to $300 \mathrm{~Hz}$. The signal was displayed on a Simonsen and Weel monitor (model MTS 102). A Gould Instruments 4 channel RS 3400 
Table 1 Details on the 23 patients in the study

\begin{tabular}{|c|c|c|c|c|c|c|c|c|c|c|c|c|c|c|}
\hline \multirow[b]{2}{*}{ Patient } & \multirow[b]{2}{*}{ Age } & \multirow[b]{2}{*}{ Sex } & \multirow{2}{*}{\multicolumn{2}{|c|}{$\begin{array}{c}\text { Previous } \\
A P M L \\
\end{array}$}} & \multirow{2}{*}{$\begin{array}{l}L V \\
\text { failure }\end{array}$} & \multirow[b]{2}{*}{ B blockade } & \multirow[b]{2}{*}{ Calcium antagonists } & \multirow{2}{*}{\multicolumn{2}{|c|}{$\begin{array}{l}\text { No of segments } \\
\text { showing abnormal } \\
\text { EF wall motion }\end{array}$}} & \multicolumn{3}{|c|}{ Coronary arteries } & \multirow[b]{2}{*}{ Group } & \multirow[b]{2}{*}{$C A B G$} \\
\hline & & & & & & & & & & $L A D$ & $C x$ & $R C A$ & & \\
\hline 1 & 53 & $M$ & + & - & - & - & - & 60 & 0 & Severe & Severe & Severe & 1 & \\
\hline 2 & 72 & $\mathbf{M}$ & + & - & - & $\begin{array}{l}\text { Atenolol } \\
50 \text { twice a day }\end{array}$ & $\begin{array}{l}\text { Nifedipine } \\
20 \text { twice a day }\end{array}$ & 82 & 0 & Severe & Severe & Severe & 1 & \\
\hline 3 & 46 & $\mathbf{M}$ & - & - & - & - & - & 79 & 0 & Mild & Normal & Normal & 1 & \\
\hline 4 & 73 & $\mathbf{M}$ & & $\begin{array}{l}\text { Large } \\
\quad \text { anterior }\end{array}$ & + & - & $\begin{array}{l}\text { Diltiazem } \\
60 \text { three times a day }\end{array}$ & 15 & $3(2 P)$ & Severe & Severe & Severe & 3 & \\
\hline 5 & 48 & $\mathbf{M}$ & + & $\begin{array}{l}\text { Inferior } \\
\quad(\times 2)\end{array}$ & - & $\begin{array}{l}\text { Metoprolol } \\
50 \text { twice a day }\end{array}$ & $\begin{array}{l}\text { Nifedipine } \\
20 \text { twice a day }\end{array}$ & 66 & 2 & Normal & $\begin{array}{c}\text { Severe } \\
\text { graft } \\
\text { open }\end{array}$ & Occluded & 3 & $\begin{array}{r}\text { RCA } \\
\text { Cx }\end{array}$ \\
\hline 6 & 61 & $\mathbf{M}$ & - & Inferior & - & $\begin{array}{l}\text { Atenolol } \\
\text { alternate days }\end{array}$ & - & 63 & 0 & Normal & Moderate & Normal & 2 & \\
\hline 7 & 52 & $\mathbf{M}$ & + & - & - & $\begin{array}{l}\text { Propranolol } \\
160 \text { once a day }\end{array}$ & $\begin{array}{l}\text { Nifedipine } \\
20 \text { twice a day }\end{array}$ & 80 & 0 & Normal & Normal & Mild & 1 & \\
\hline 8 & 52 & $\mathbf{M}$ & + & - & - & $\begin{array}{l}\text { Atenolol } \\
100 \text { once a day }\end{array}$ & $\begin{array}{l}\text { Diltiazem } \\
60 \text { twice a day }\end{array}$ & 79 & 0 & $\begin{array}{l}\text { Occluded } \\
\text { OM }\end{array}$ & Normal & Severe & 1 & \\
\hline 9 & 61 & $\mathbf{M}$ & $\star$ & - & - & - & - & 83 & 0 & Normal & Normal & Normal & 1 & \\
\hline 10 & 51 & $\mathbf{M}$ & + & Lateral & - & $\begin{array}{l}\text { Atenolol } \\
50 \text { twice a day }\end{array}$ & $\begin{array}{l}\text { Nifedipine } \\
10 \text { twice a day }\end{array}$ & 84 & 0 & Moderate & Moderate & Moderate & 2 & \\
\hline 11 & 56 & $\mathbf{M}$ & + & Lateral & - & $\begin{array}{l}\text { Atenolol } \\
50 \text { once a day }\end{array}$ & - & 46 & 1 & Mild & Normal & Severe & 3 & \\
\hline 12 & 53 & $\mathbf{M}$ & - & Inferior & - & $\begin{array}{l}\text { Atenolol } \\
50 \text { once a day }\end{array}$ & - & 54 & 2 & Mild & Moderate & Mild & 3 & \\
\hline 13 & 57 & $\mathbf{M}$ & + & $\begin{array}{l}\text { Inferior } \\
\text { apex } \\
\text { lateral }\end{array}$ & + & - & $\begin{array}{l}\text { Nifedipine } \\
10 \text { three times a day }\end{array}$ & 59 & $2(1 P)$ & Moderate & Normal & Moderate & 3 & \\
\hline $\begin{array}{l}14 \\
15\end{array}$ & $\begin{array}{l}49 \\
59\end{array}$ & $\begin{array}{l}\mathrm{F} \\
\mathbf{M}\end{array}$ & * & $\overline{+}$ & - & $\begin{array}{l}\overline{\text { Atenolol }} \\
50 \text { once a day }\end{array}$ & $\overline{-}$ & $\begin{array}{l}68 \\
75\end{array}$ & $\begin{array}{l}0 \\
0\end{array}$ & $\begin{array}{l}\text { Normal } \\
\text { Normal }\end{array}$ & $\begin{array}{l}\text { Normal } \\
\text { Normal }\end{array}$ & $\begin{array}{l}\text { Normal } \\
\text { Normal }\end{array}$ & $\begin{array}{l}1 \\
2\end{array}$ & \\
\hline 16 & 58 & $\mathbf{M}$ & + & + & - & - & $\begin{array}{l}\text { Nifedipine } \\
20 \text { twice a day }\end{array}$ & 64 & 1 & Occluded & Normal & Ectatic & 3 & \\
\hline 17 & 48 & $\mathbf{M}$ & + & + & - & $\begin{array}{l}\text { Metoprolol } \\
50 \text { twice a day }\end{array}$ & $\begin{array}{l}\text { Diltiazem } \\
60 \text { three times a day }\end{array}$ & 80 & 1 & $\begin{array}{l}\text { Occluded } \\
\text { graft } \\
\text { open }\end{array}$ & $\begin{array}{l}\text { Occluded } \\
\text { graft } \\
\text { open }\end{array}$ & Moderate & 3 & $\underset{\text { LAD }}{\mathrm{Cx}}$ \\
\hline 18 & 59 & $\mathbf{F}$ & + & + & - & - & $\begin{array}{l}\text { Nifedipine } \\
20 \text { three times a day }\end{array}$ & 25 & 4 & Severe & Severe & $\begin{array}{l}\text { Tight } \\
\text { mid }\end{array}$ & 3 & \\
\hline 19 & 65 & $\mathbf{M}$ & + & + & + & $\begin{array}{l}\text { Atenolol } \\
100 \text { once a day }\end{array}$ & $\begin{array}{l}\text { Nifedipine } \\
20 \text { three times a day }\end{array}$ & 32 & 2 & $\begin{array}{l}\text { Occluded } \\
\text { graft } \\
\text { open }\end{array}$ & $\begin{array}{l}\text { Occluded } \\
\text { graft } \\
\text { open }\end{array}$ & $\begin{array}{l}\text { Occluded } \\
\text { graft } \\
\text { open }\end{array}$ & 3 & $\begin{array}{r}\text { Cx } \\
\text { LAD } \\
\text { RCA }\end{array}$ \\
\hline 20 & 49 & $\mathbf{M}$ & + & + & - & $\begin{array}{l}\text { Atenolol } \\
50 \text { once a day }\end{array}$ & $\begin{array}{l}\text { Nifedipine } \\
20 \text { twice a day }\end{array}$ & 76 & 0 & Moderate & Moderate & Moderate & 2 & \\
\hline 21 & 52 & $\mathbf{F}$ & + & Anteroseptal & $1-$ & $\begin{array}{l}\text { Propranolol } \\
160 \text { one a day }\end{array}$ & $\begin{array}{l}\text { Diltiazem } \\
60 \text { three times a day }\end{array}$ & 58 & 2 & Mild & Normal & Severe & 3 & \\
\hline $\begin{array}{l}22 \\
23\end{array}$ & $\begin{array}{l}33 \\
52\end{array}$ & $\begin{array}{l}\mathbf{M} \\
\mathbf{M}\end{array}$ & $\overline{-}$ & $\begin{array}{l}+ \\
-\end{array}$ & $\overline{-}$ & $\overline{-}$ & $\begin{array}{l}\bar{N}_{\text {Nifedipine }} \\
20 \text { twice a day }\end{array}$ & 78 & 0 & Severe & Normal & Moderate & $2 \dagger$ & \\
\hline
\end{tabular}

‡Non-specific chest pain; †cardiac transplant.

$\mathrm{AP}$, angina pectoris; MI, myocardial infarction; LV, left ventricle; $\mathrm{EF}$, ejection fraction; LAD, left anterior descending; $\mathrm{Cx}$, circumflex; RCA, right coronary artery; $\mathrm{CABG}$, coronary artery bypass graft; $\mathrm{P}$, paradoxical motion; $\mathrm{OM}$, obtuse marginal.

chart recorder (model 30-V8404-10) was used for hard copy recordings at a paper speed of 125 $\mathrm{mm} / \mathrm{s}$. Hard copy recordings of the routine blood pressure were also recorded in order to synchronise the blood pressure measurements with the monophasic action potentials on a beat to beat basis. The routine electrocardiogram monitored at the time was also recorded. The monophasic action potential recording was calibrated with a direct current millivolt source (Time Electronics model 4045). The blood pressure was calibrated against known pressures of 0 and $100 \mathrm{~mm} \mathrm{Hg}$.

\section{PROCEDURE}

Routine coronary angiography, via the right femoral artery by the Judkins technique, was performed on all patients (except patient number 23). Left ventricular angiography was performed in the right anterior oblique position. Patient 23 had a left ventricular biopsy only (no coronary angiography or left ventricular angiography).

On completion of the routine procedure the angiography catheter (or biopsy catheter) was replaced with the monophasic action potential catheter which was positioned against the left ventricular wall. Right atrial pacing was established via the right femoral vein at a rate of approximately $15 \%$ above the patient's resting heart rate. Two patients ( 2 and 3 ) were unpaced but were included because the heart rate from control to phase IIA and from phase III to IVA did not change by more than $1 \%$.

\section{VALSALVA MANOEUVRE}

The apparatus used for the Valsalva manoeuvre consisted of a $20 \mathrm{ml}$ syringe for a mouthpiece (plunger removed) attached via rubber tubing to a sphygmomanometer. The size of the syringe ensured a tight seal between the patient's lips and the barrel of the syringe. The patient was asked to blow hard and maintain the mercury column at $40 \mathrm{~mm} \mathrm{Hg}$ for 15 seconds.

A run-in period of atrial pacing for two minutes established a steady state after which continuous recordings were made during the Valsalva manoeuvre. When feasible the procedure was repeated for up to three times. There was a rest period of three minutes between procedures during which atrial pacing was maintained.

\section{ANALYSIS OF DATA}

Monophasic action potential duration was measured at $90 \%$ and $70 \%$ repolarisation. The terminal portion of the action potential was defined by drawing a tangent to the fastest part of the downstroke to the baseline. ${ }^{4142}$ This 


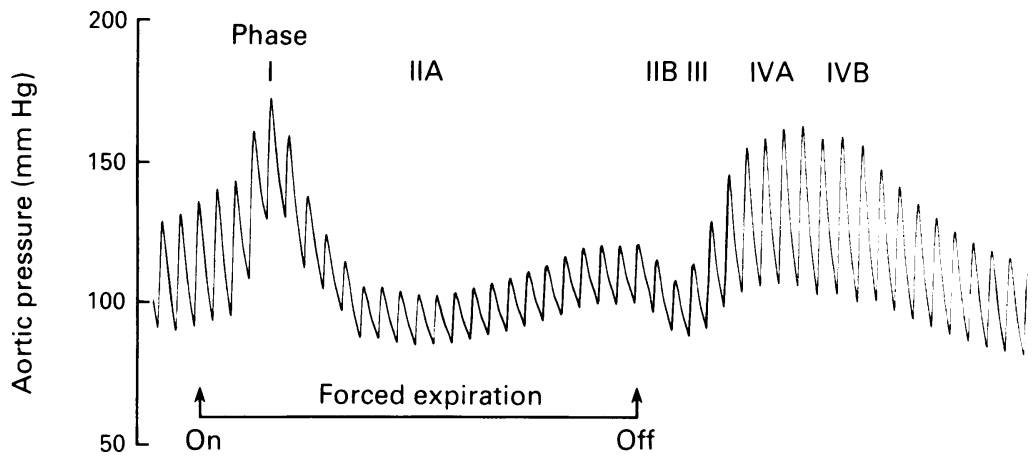

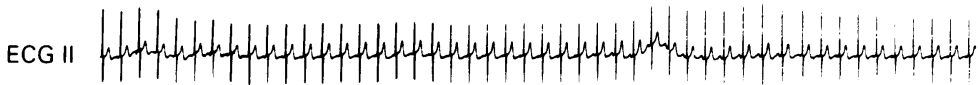
Atrial pacing

Figure 1 Typical recording of aortic blood pressure during the Valsalva manoeuvre together with the routine electrocardiogram. The four phases of the Valsalva manoeuvre and duration of the forced expiration are shown. Cycle length $=670 \mathrm{~ms}$.

method eliminated the possibility of including afterdepolarisations in the measurements which would have produced long duration action potentials. In addition this technique of measurement also overcomes possible difficulties in measuring action potentials exhibiting a continuous decline of phase IV. Mean values with standard deviations are presented. The data were assessed by a repeated measures analysis of variance and planned comparison of means (Anova)

\section{Results}

Figure 1 shows a typical blood pressure response to the Valsalva manoeuvre we obtain in our catheter laboratory. The patient takes a deep breath in and then blows hard against a calibrated resistance of $40 \mathrm{~mm} \mathrm{Hg}$. This increases the intrathoracic and intraabdominal pressures thereby impeding venous return, reducing ventricular filling, and reducing left ventricular systolic pressure and volume. Four phases are described. The initial increase in blood pressure seen in phase I lasts for a few beats only and is due to a direct effect of the increased intrathoracic pressure, possibly together with an increased preload caused by a shift of blood from the pulmonary bed into the left ventricle. During phase II there is an initial fall in blood pressure (phase IIA) because venous return is impeded. This results in a reflex increase in peripheral resistance and inotropic state of the myocardium curtailing the fall in blood pressure and resulting in a plateau and even a small subsequent rise (phase IIB). After release of the forced expiration intrathoracic pressure returns to normal and refilling of the pulmonary vascular bed results in a transient further fall in blood pressure caused by a further reduction in ventricular filling for about 2-3 beats (phase III). As the venous return is restored and ventricular filling increases the blood pressure rises (phase IV). Reflex autonomic effects may cause an "overshoot" above control levels of blood pressure (phase IVB).

During the Valsalva manoeuvre there were considerable changes in the time course of repolarisation in the recordings of endocardial monophasic action potential coincident with the changes in blood pressure.

Figure 2 shows the changes typical of monophasic action potential in a patient with no angiographic evidence of abnormal wall motion (group 1). During the strain phase (B) the monophasic action potential duration shortened and subsequently increased after release (C). Action potential duration was measured at $90 \%$ repolarisation.

In group 3 (those with regional wall abnormalities) there were 21 observations during the strain phase and 20 during the release phase. During the strain phase the direction of change
Figure 2 Tracing of monophasic action potentials and aortic pressure before the Valsalva manoeuvre (beats 3-8) during the strain phase (phase II, beats 17-22), and from the release of forced expiration (phase III) (after beat 29 to beat 34). Zero calibration for the monophasic action potentials is shown at the end of the second ponel. Cycle length $=584 \mathrm{~ms}$. (Group 1 patient)

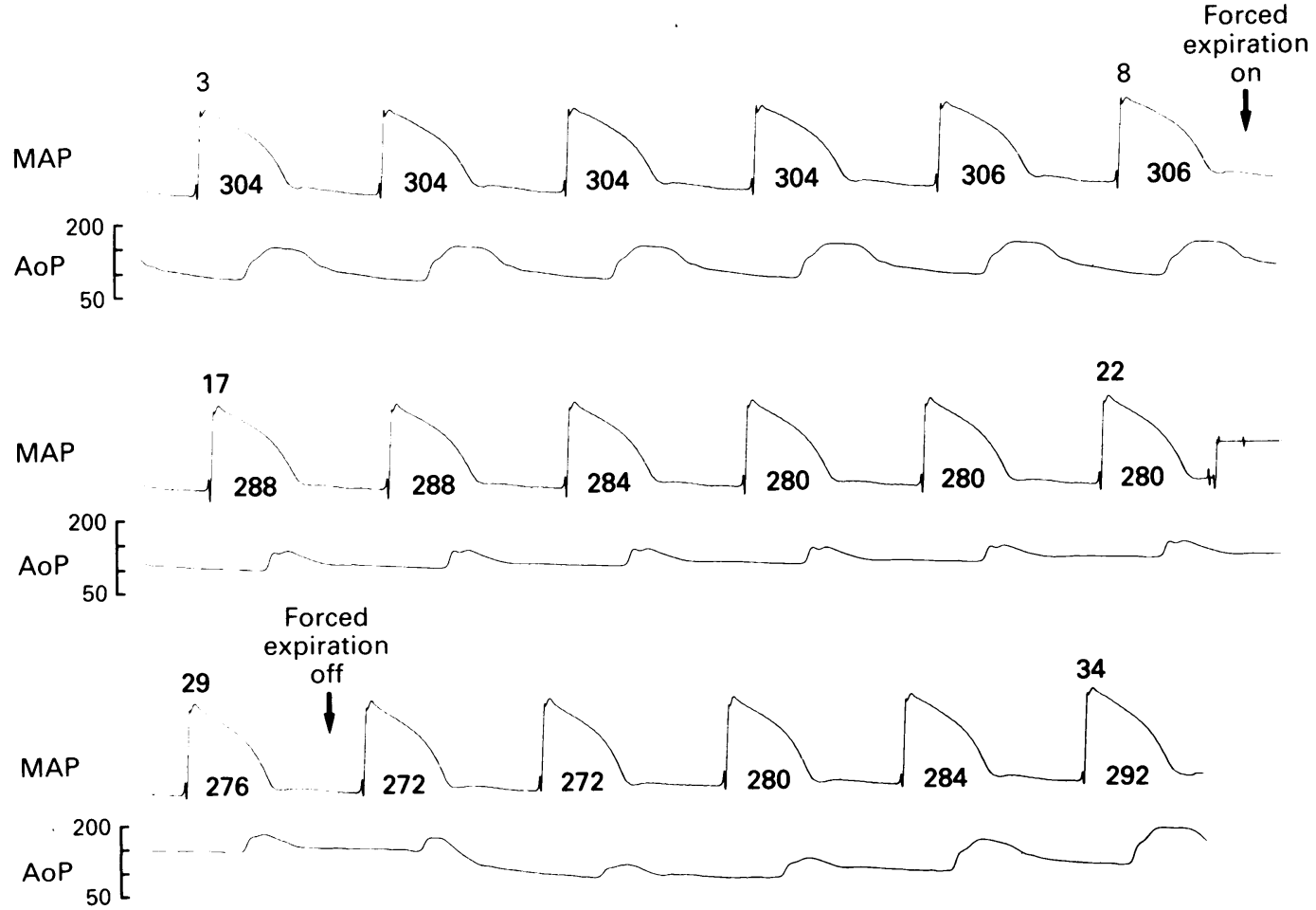


Figure 3 Continuous recording of monophasic tion potential and aortic pressure during the strain phase of the Valsalva manoeuvre in a patient with abnormal wall motion and a history of

myocardial infarction

(group 3). Monophasic action potential duration (at $90 \%$ repolarisation) increased progressively from $260 \mathrm{~ms}$ to $296 \mathrm{~ms}$ as peak systolic pressure fell. The fast phase of repolarisation became progressively delayed possibly representing early afterdepolarisations. Cycle length $=496 \mathrm{~ms}$
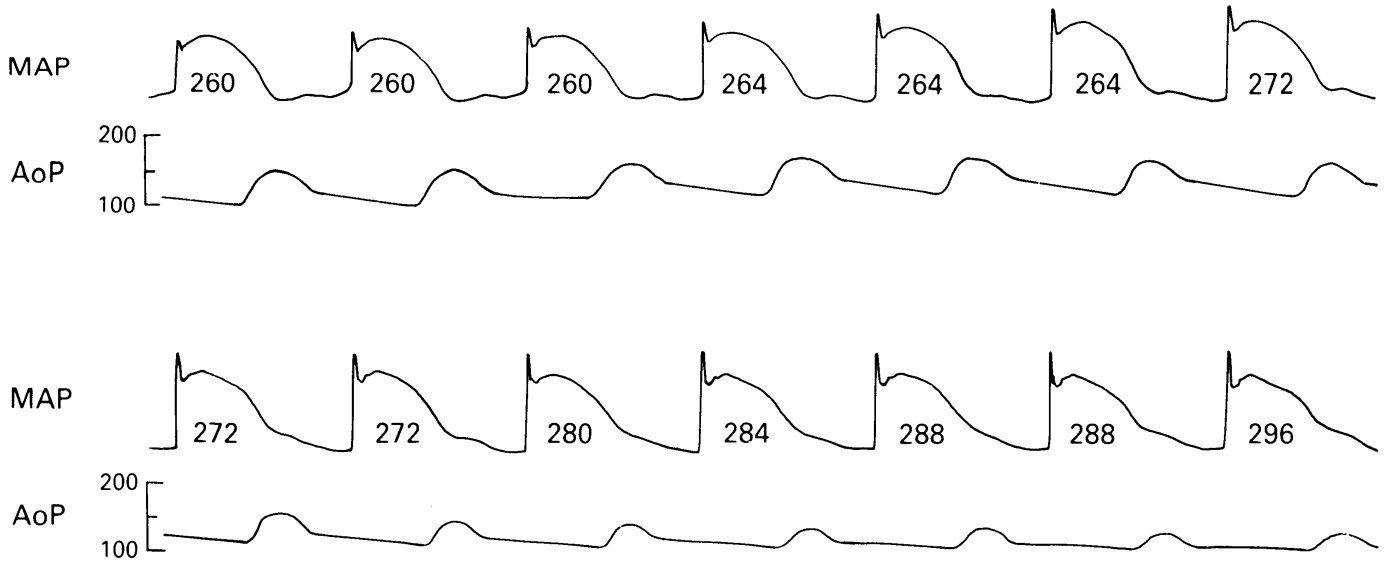

of action potential duration was normal in seven observations, abnormal in six, and showed no clear change in eight. During the release phase 11 were normal, five abnormal, and four showed no clear change. Figure 3 shows an example of changes in monophasic action potential duration which were opposite in direction. Action potential duration increased as systolic pressure fell during the strain phase. In addition the late phase of repolarisation became progressively delayed; this may have represented an afterdepolarisation.

Figure 4 shows the changes in monophasic action potential duration for the first nine beats of the strain phase and the release phase for each patient. Each patient performed up to three Valsalva manoeuvres. The vertical bars indicate the change in monophasic action potential duration with respect to the action potential duration at the start of each phase. As indicated by the scale a bar below the baseline represents a shortening whereas a bar above represents a lengthening. In group 1 there was uniform shortening in the strain phase and uniform lengthening during the release phase. In group 3 this symmetry was no longer apparent with many patients showing changes in the opposite directions to those in group 1. Changes in the opposite direction in at least one

Table 2 Monophasic action potential duration (ms) (mean (SD)) at $90 \%$ repolarisation at $70 \%$ repolarisation and peak systolic pressure (mmHg) at phases I, IIA,III, IVA and IVB of the Valsalva manoeuvre for patients with no abnormal wall motion and no history of previous myocardial infarction (group 1), those with previous history of myocardial infarction but normal wall motion (group 2), patients with abnormal wall motion (group 3), and for all three groups.

\begin{tabular}{|c|c|c|c|c|c|}
\hline & \multicolumn{2}{|l|}{ Strain phase } & \multirow[b]{2}{*}{$I I I$} & \multicolumn{2}{|l|}{ Release phase } \\
\hline & $I$ & $I I A$ & & $I V A$ & $I V B$ \\
\hline \multicolumn{6}{|c|}{ At $90 \%$ repolarisation } \\
\hline Group 1 & $311(47) \frac{0.001}{n=14}$ & $295(47)$ & $285(44) \frac{0.0001}{n=14}$ & $\begin{array}{l}304(44) \\
305(50) \frac{0.001}{\mathrm{n}=11}\end{array}$ & $293(48)$ \\
\hline Group 2 & 274 (29) $\frac{\mathrm{NS}}{\mathrm{n}=9}$ & $269(27)$ & 265 (27) $\underset{\mathrm{n}=8}{\mathrm{NS}}$ & $\begin{array}{l}271(29) \\
270 \text { (30) } \frac{0.005}{\mathrm{n}=7}\end{array}$ & $277(31)$ \\
\hline Group 3 & 285 (33) $\frac{N S}{n=21}$ & $287(28)$ & $279(30) \frac{N S}{n=20}$ & $\begin{array}{l}285(35) \\
280(35) \frac{N S}{n=15}\end{array}$ & $278(34)$ \\
\hline Groups 1,2 and 3 & 291 (39) $\frac{0.02}{\mathrm{n}=44}$ & $286(36)$ & 279 (35) $\frac{0.001}{\mathrm{n}=42}$ & $289(38) \frac{N S}{n=33}$ & $283(38)$ \\
\hline \multicolumn{6}{|c|}{ At $70 \%$ repolarisation } \\
\hline Group 1 & $282(47) \frac{0.001}{\mathrm{n}=14}$ & $268(48)$ & 259 (46) $\frac{0.0001}{\mathrm{n}=14}$ & $\begin{array}{l}271(43) \\
271(49) \frac{0.015}{\mathrm{n}=11}\end{array}$ & $262(47)$ \\
\hline Group 2 & 249 (30) $\frac{0-002}{\mathrm{n}=9}$ & $239(29)$ & 234 (28) $\frac{0.05}{n=8}$ & $\begin{array}{l}242 \text { (27) } \\
241 \text { (29) } \frac{0.009}{n=7}\end{array}$ & $250(31)$ \\
\hline Group 3 & 257 (32) $\frac{\mathrm{NS}}{\mathrm{n}=21}$ & $256(26)$ & $249(21) \frac{0.015}{n=20}$ & $\begin{array}{l}257 \text { (37) } \\
247(29) \frac{N S}{n=15}\end{array}$ & $246(29)$ \\
\hline Groups 1,2 and 3 & 263 (39) $\frac{0.0001}{\mathrm{n}=44}$ & $256(36)$ & 249 (34) $\frac{0.0001}{n=42}$ & $\begin{array}{l}250(36) \text { NS } \\
254(38) \frac{\mathrm{n}=33}{\mathrm{n}=}\end{array}$ & $252(36)$ \\
\hline \multicolumn{6}{|c|}{ Peak systolic pressure ( $\mathrm{mm} \mathrm{Hg}$ ) } \\
\hline Group 1 & $138(31) \frac{0.02}{\mathrm{n}=14}$ & $97(37)$ & $66(26) \frac{0.0001}{n=14}$ & $109(32) \frac{0.001}{108(36)}$ & $145(33)$ \\
\hline Group 2 & 167 (23) $\frac{0.039}{n=9}$ & $110(19)$ & 86 (15) $\frac{0.0001}{n=8}$ & $\begin{array}{l}134 \text { (18) } \\
138 \text { (15) } \frac{0.001}{\mathrm{n}=7}\end{array}$ & $174(22)$ \\
\hline Group 3 & $160(17) \frac{0.0001}{\mathrm{n}=21}$ & $127(25)$ & 107 (32) $\frac{0.0001}{\mathrm{n}=20}$ & $\begin{array}{l}135(35) \\
130(23) \frac{0.0001}{n=14}\end{array}$ & $170(27)$ \\
\hline Groups 1,2 and 3 & 155 (25) $\frac{0 \cdot 0001}{\mathrm{n}=44}$ & $114(31)$ & 89 (33) $\frac{0.001}{n=42}$ & $126(29) \frac{0.0001}{n=32}$ & $162(30)$ \\
\hline
\end{tabular}


A
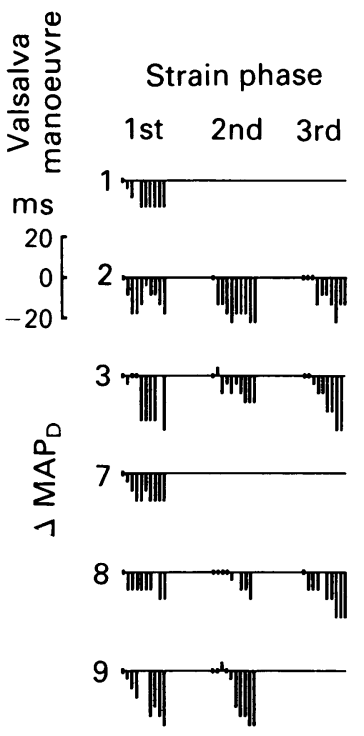

14
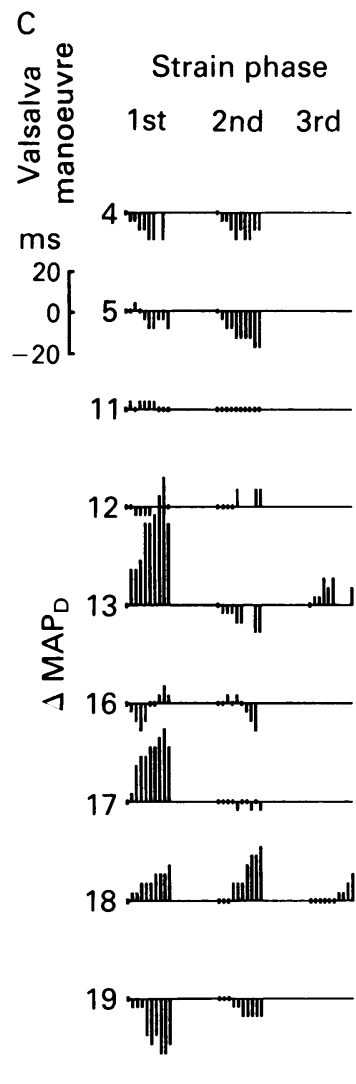

21

of the manoeuvres was seen in six of the patients. In particular, some patients (for example, case 16) occasionally showed changes in the opposite direction during consecutive Valsalva manoeuvres with the recording electrode positioned at adjacent sites. In group 2 patients in general the changes resembled those in group 1 but were not always as clear cut.

Table 2 shows the mean values. Group 1 patients showed highly significant changes in action potential duration in both phases, reflecting the uniform direction of change in all patients. The lack of uniformity seen in group 3 patients is reflected in the seemingly smaller

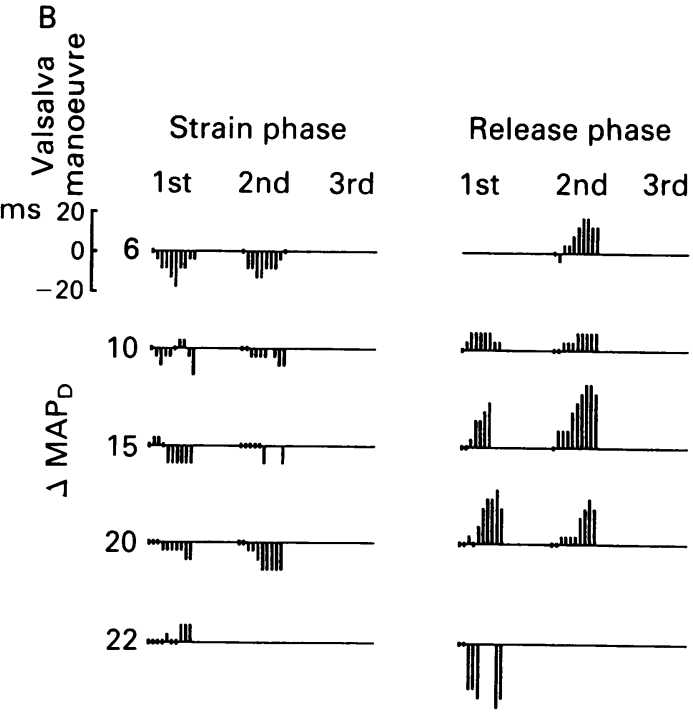

Figure 4 Changes in monophasic action potential duration at $90 \%$ repolarisation $\left(M A P_{D}\right)$ during the first nine beats of the strain phase of the Valsalva manoeuvre (from phase I) and during the first four beats after release (from phase III). Between one and three consecutive Valsalva manoeuvres were monitored in patients each from a different site. (A) Patients with no history of myocardial infarction and no angiographic evidence of abnormal wall motion, $(B)$ patients with a history of myocardial infarction but no angiographic evidence of abnormal wall motion, $(C)$ patients with abnormal wall motion either with or without a history of myocardial infarction. The first point (0) in each histogram in each phase is the starting point and subsequent values are the change in milliseconds. Some bars are missing and the bars in patient 13 overlap those in patient 12.

changes in the mean values particularly at $90 \%$ repolarisation. The changes in mean values for group 2 patients in general followed the pattern seen in group 1.

The possible presence of afterdepolarisations seen in fig 3 was also seen in two other patients and an example is shown in fig 5 . Figure 5 again represents the progressive development of "afterdepolarisations" in another patient from this group which culminates in a ventricular extrasystole.

We compared the changes in monophasic action potential duration for each of the phases of the Valsalva manoeuvre in patients taking $\beta$ blockers with those who were not. The only significant difference was during phase IIA in patients in group $1(p<0.03)$ and combined groups 1 and $2(\mathrm{p}<0.04)$-that is, all patients without abnormal wall motion.

We studied one additional patient who had received a donor heart six months previously. The changes in monophasic action potential duration in this patient were not included in the statistical analysis. However, monophasic action potential duration changed in a manner similar to those in group 1. Two Valsalva manoeuvres were recorded. The aortic pressure record was almost identical for both runs. In figure 6 the aortic pressure tracing is shown together with beat by beat changes in monophasic action potential duration at $90 \%$ and $70 \%$ repolarisation for the strain phase (from run one) and the release phase (from run two). Figure 7 shows the monophasic action 


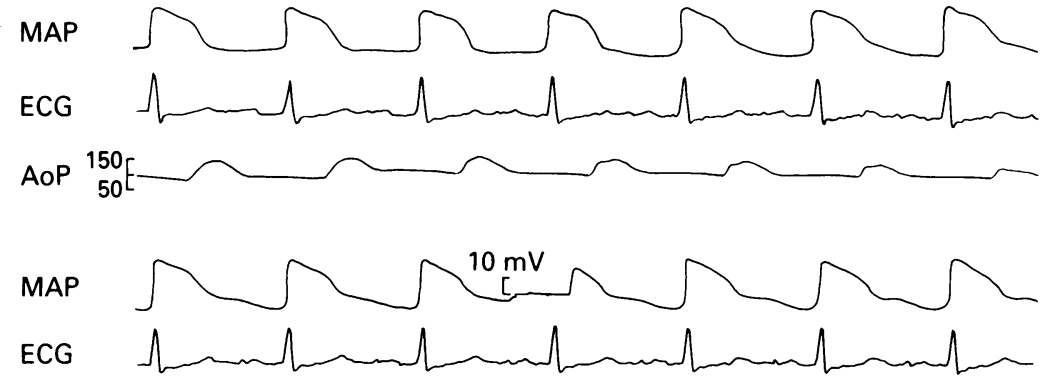

AoP ${ }_{50}^{150}[$

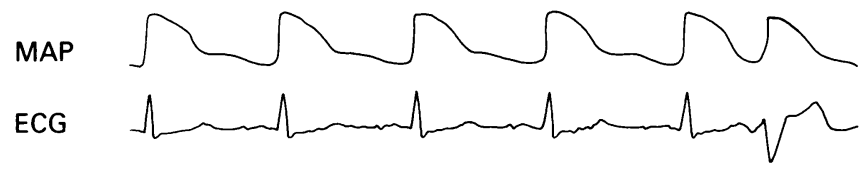

AoP ${ }^{150} \mathrm{E}$

Figure 5 Continuous tracings of monophasic action potential, aortic pressure recording, and electrocardiogram (lead II) during phase II of the Valsalva manoeuvre in a patien with abnormal wall motion and a history of myocardial infarction. The fast phase of repolarisation became progressively delayed culminating in a ventricular extrasystole (arrow). Zero calibration for the monophasic action potential is included between the third and fourth beats in the middle panel. Cycle length $=664 \mathrm{~ms}$.

potentials during the early strain phase. During this strain phase the monophasic action potential duration shortened progressively as aortic pressure fell.

\section{Discussion}

Abnormal left ventricular wall motion is a major predictor of sudden cardiac death ${ }^{12}$ that is often considered to be the result of arrhythmia. $^{6-8}$ The mechanism for this relation remains undefined. We examined the effect of acute ventricular pressure/volume changes on

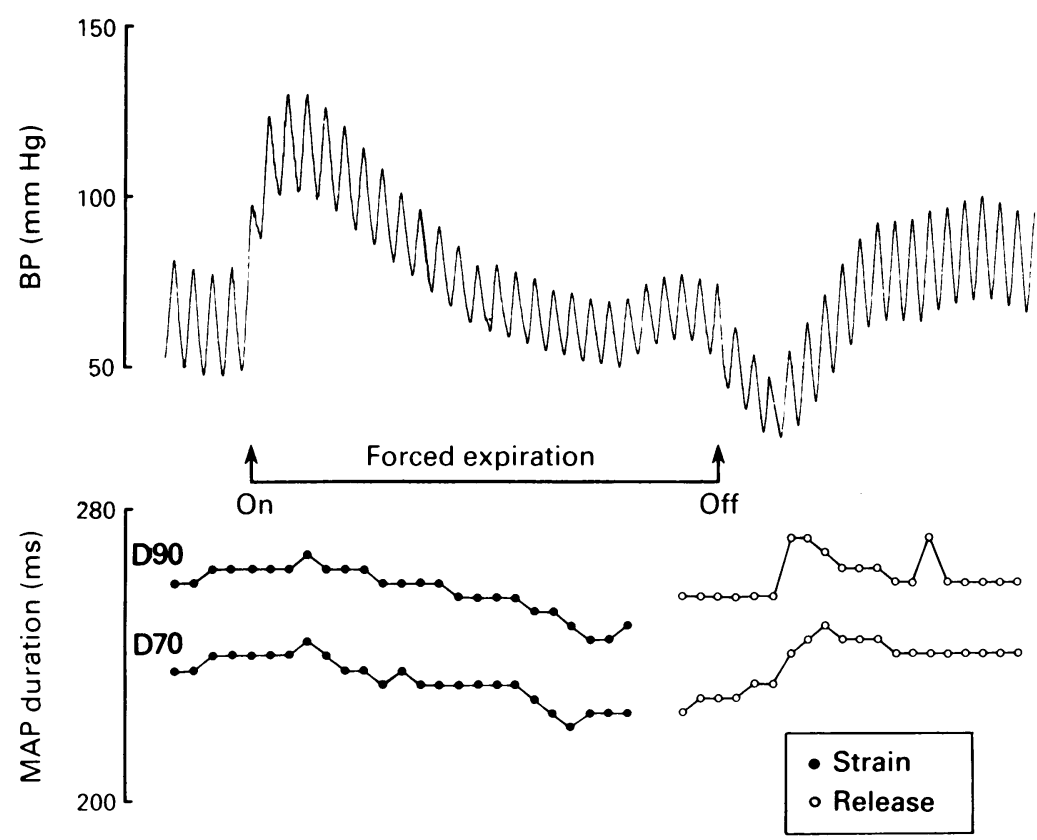

Figure 6 Aortic pressure tracing during the Valsalva manoeuvre in an orthotopic transplanted heart six months after the operation. Beat by beat plot of action potential duration at $90 \%$ repolarisation is shown below. Action potential duration during the ventricular loading phase was obtained from a repeat Valsalva manoeuvre in this patient which produced an identical blood pressure profile. During ventricular unloading the action potential duration shortened and subsequently lengthened during the subsequent loading phase. ventricular repolarisation in patients with normal and with abnormal wall motion to see whether there were any electrophysiological changes that would be in keeping with those required for arrhythmia formation. A convenient means of altering ventricular pressure/ volume is the Valsalva manoeuvre in which a forced expiration impedes venous return, causing a reduction of left ventricular pressure/ volume. ${ }^{33-35} \mathrm{We}$ recorded monophasic action potentials from the left ventricular endocardium as a measure of the time course of repolarisation. We found significant changes in the timing of regional ventricular repolarisation during the Valsalva manoeuvre. In some patients with abnormal wall motion the effects on ventricular repolarisation were opposite in direction to those found in patients with normal wall motion. In both groups of patients the change in the duration of repolarisation in response to changes in ventricular loading suggests that the mechanical effects of the loading may play a part in these changes. It may be argued that the autonomic influences associated with the Valsalva manoeuvre ${ }^{33-35}$ may also contribute to our findings because increased sympathetic activity may influence the timing of repolarisation ${ }^{43-45}$ (that is, action potential duration). We consider that this contribution is minimal because we confirmed our observations on ventricular unloading to the first few beats-before significant autonomic effects occur. ${ }^{46}$ Our observations during ventricular loading were confined to a four beat train during which time changes in autonomic tone would be small. In addition the changes in action potential duration in the transplanted heart, which is devoid of innervation, were comparable in direction to those in our normal patients (group 1). Finally there was no difference in the response in patients receiving $\beta$ blockade compared with those who were not.

If we accept that the effects that we have seen are mechanical-in that the changes in ventricular loading directly influence the timing of repolarisation-then our results would be consistent with contraction-excitation feedback. Such a mechanism has been demonstrated experimentally in isolated tissues and in animals. In general, it has been shown that increasing the length of cardiac muscle shortens the action potential duration and decreasing the length of the muscle lengthens the action potential duration. ${ }^{16}$ Our patients with normal wall motion (group 1), however, showed opposite effects. A reduction left ventricular volume and peak systolic pressure shortened the monophasic action potential duration and an increase in left ventricular volume and peak systolic pressure lengthened it.

It is probable that several mechanisms are involved-such as stretch and fibre excursion. It has been shown that there is a relation between the extent to which a muscle is allowed to shorten and the duration of the action potential. For example when a contracting muscle is prevented from shortening (that is, isometric contraction) the action potential duration is abbreviated. In the unloading phase 

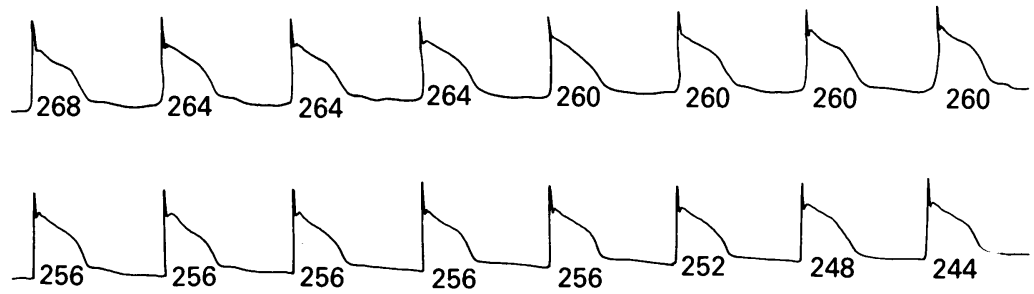

Figure 7 A continuous recording of monophasic action potentials during the strain phase in the patient in figure 7. Monophasic action potential duration is shown at $90 \%$ repolarisation and shortened progressively from $268 \mathrm{~ms}$ to $244 \mathrm{~ms}$. Cycle length $=584 \mathrm{~ms}$. our experience only slight changes in action potential duration were caused by spontaneous variability. Prematurity shortens action potential duration, which depends on the rate and preceding cycle length. For example, during a steady state heart rate of $80 /$ minute (cycle length $750 \mathrm{~ms}$ ) an early beat of $350 \mathrm{~ms}$ shortened the action potential by about $11 \mathrm{~ms} .^{53}$

Arrhythmia in patients with coronary heart disease and congestive heart failure is probably multifactorial, ${ }^{15}$ with deaths in some instances being due to electromechanical dissociation. In addition to contraction-excitation feedback (or mechano-electric coupling) other important factors may be myocardial fibrosis and hypertrophy ${ }^{54}$ activation of the sympathetic nervous system or hypokalaemia induced by a renin angiotensin system ${ }^{55}$ diuretic, ${ }^{56}$ together with the arrhythmogenic effect of drug treatment such as digoxin and some antiarrhythmic agents. Studies of an animal model of doxorubicin induced heart failure suggest an inherent mechanism not related to mechanical or any of the above effects. ${ }^{57}$ Our results, however, support the possibility that mechanically induced electrophysiological changes could play a part in these clinical situations. ${ }^{58}$

Our study confirms that potentially arrhythmogenic changes in action potential duration and excitability in humans may be produced by load changes that are within physiological ranges ${ }^{59}$ and that changes in ventricular loading change the time course of repolarisation. An important finding was that such changes could be in opposite directions in patients with normal wall motion and patients with abnormal wall motion. These data suggest that the presence of abnormal wall motion may induce electrophysiological changes by contractionexcitation feedback and this may provide a link between the unexplained association between arrhythmia and impaired left ventricular function.

This study was supported by a grant from the British Heart Foundation. depolarisations recorded with microelectrodes. ${ }^{49}$ It may be important that in our study they were accompanied by extrasystoles. These could be attributed to local irritation by the stiff catheter, but extrasystoles have also been seen by various recording techniques in several experimental preparations. ${ }^{16202125}$ We saw some considerable early afterdepolarisations (figs 3 and 5) which were particularly obvious in patients with abnormal wall motion. In the example shown in fig 5 the progressive increase in afterdepolarisations culminated in an extrasystole. In some instances we saw a continuous decline in phase IV even after the termination of the possible afterpotential was seen. We cannot say whether these were artefacts or real phenomena.

There was a wide variability in the size of the effect on action potential duration, which varied from $20 \mathrm{~ms}$ to $40 \mathrm{~ms}$ in some patients (fig 4). This is greater than the dispersion necessary to facilitate reentrant arrhythmias ${ }^{50}{ }^{51}$ and not dissimilar to action potential durations induced by antiarrhythmic drugs with class III action. ${ }^{52}$ In

Weaver WD, Lorch GS, Alvarez HA, Cobb LA. Angiographic findings and prognostic indicators in patients resuscitated from cardiac death. Circulation 1976;54: 895-900.

2 Schultz RA, Strauss HW, Pitt B. Sudden death in the year following myocardial infarction: relation to ventricular premature contractions in the late hospital phase and left ventricular ejection fraction. Am J Med 1977;62:192-9.

3 Multicentre Postinfarction Research Group. Risk stratification and survival after myocardial infarction. $N$ Engl J tion and survival after
Med 1983;309:331-6.

4 White HD, Norris RN, Brown MA, Brandt PW, Whitlock RML, Wild CJ. Left ventricular end systolic volume as the major determinant of survival after recovery from the major determinant of survival after recovery

5 Meizlish JL, Berger HJ, Plankey M, Errico D, Levy W, Zaret BL. Functional left ventricular aneurysm formation after acute transmural myocardial infarction. $N$ Engl $J$ Med 1984;311:1001-6.

6 Calvert A, Lown B, Gorlin R. Ventricular premature beats and anatomically defined coronary heart disease. $\mathrm{Am} \mathrm{J}$ Cardiol 1977;39:627-34

Califf RM, Burks JM, Behar VS, Margolis JR, Wagner GS. Relationships among ventricular arrhythmias, coronary artery disease and angiographic and electrocardiographic indicators of myocardial fibrosis. Circulation 1978;57: 725-32.

8 Califf RM, Mckinnis RA, Burks J, et al. Prognostic implications of ventricular arrhythmias during 24 hour ambulatory monitoring in patients undergoing cardiac catheterization for coronary artery disease. Am J Cardio 1982;50:23-31. 
9 Santinga JT, Kirsh MM, Brady TJ, Thrall J, Pitt B. Left ventricular function in patients with ventricular ventricular function in patients with ventricular
arrhythmias and aortic valve disease. Ann Thorac Surg arrhythmias and

10 Klein RC. Ventricular arrhythmias in aortic valve disease: analysis of 102 patients. Am J Cardiol 1984;53:1079-83.

11 Kostis JB, Tupper B, Moreyra AE, Hosler M, Cosgrove N Terrigino C. Aortic valve replacement in patients with aortic stenosis. Effect on cardiac arrhythmias. Ches 1984;85:211-4.

12 Swerdlow CD, Winkle RA, Mason JW. Determinants of survival in patients with tachyarrhythmias. $N$ Engl J Med 1983;308:1436-42.

13 Wilson JR, Schwartz JS, Sutton MS, et al. Prognosis in severe heart failure. Relation to haemodynamic measurements and ventricular ectopic activity. J Am Coll Cardiol 1983;2:403-10.

14 Holmes J, Kubo SH, Cody RJ, Klingfield P. Arrhythmias in ischaemic and non-ischaemic dilated cardiomyopathy: prediction of mortality by ambulatory electrocardiography. Am J Cardiol 1985;55:146-51.

15 Dargie HJ, Cleland JFG, Leckie BJ, Inglis CG, East BW, Ford I. Relation of arrhythmias and electrolyte abnormalities to survival in patients with

16 Lab MJ. Contraction-excitation feedback in myocardium: physiological basis and clinical relevance. Circ Res physiological basis

17 Janse MJ, Kleber AG. Electrophysiological changes and ventricular arrhythmias in the early phase of regional myocardial ischemia. Circ Res 1981;49:1069-81.

18 Tyberg JV, Forrester JS, Parmley WW. Altered segmental function and compliance in acute myocardial ischemia. Eur J Cardiol 1974;1:307-17.

19 Forrester JS, Wyatt HL, da Luz PL, Typerg JV, Diamond $\mathrm{GA}$, Swan HJC. Functional significance of regiona ischemic contraction abnormalities. Circulation 1976;54:64-70.

20 Kaufmann RL, Lab MJ, Hennekes R, Krause H. Feedback interaction of mechanical and electrical events in the
isolated mammalian ventricular myocardium (cat papillary muscle) Pflugers Arch 1971;324:100-23.

21 Franz MR, Burkhoff D, Yue DT, Sagawa K. Mechanically induced action potential changes and arrhythmia in isolated and in situ canine heart. Cardiovasc Res 1989;23:213-23.

22 Lerman BB, Burkhoff D, Yue DT, Sagawa K. Mechanoelectrical feedback. Independent role of preload and clectrical feedback. Independent role of preload and contractility in modulation of canine

23 Calkins $H$, Jughan $\mathrm{W}$, Weisman HF, Sugiura S, Sagawa K, Levine JH. Effects of acute volume load on refractoriness Levine JH. Effects of acute volume load on refractoriness and arrhythmia development in isolated chronical

24 Benditt DG, Kriett JM, Tobler HG, Gornick CC, Detlof BLS, Anderson RW. Electrophysiological effects of transient aortic occlusion in intact canine heart. $A m$ Physiol 1985;249:H1017-23.

25 Lab MJ. Contribution of mechano-electric coupling to ventricular arrhythmias during reduced perfusion. Int $J$ Microcirc Clin Exp 1989;8:433-42.

26 Dean JW, Dilly SG, Lab MJ. Increased afterload shortens the absolute refractory period in situ left ventricle of anaesthetised pig. J Physiol (Lond) 1987;387:7P.

27 Reiter MJ, Synhorst DP, Mann DE. Electrophysiological effects of acute ventricular dilatation in the isolated rabbit heart. Circ Res 1988;62:554-62.

28 Hansen DE, Craig CS, Hondeghem LM. Stretch-induced arrhythmias in isolated canine ventricle. Evidence for the importance of mechanoelectrical feedback. Circulation importance of mech

29 Calkins H, Maughan WL, Kass DA, Sagawa K, Levine JH. Electrophysiological effect of volume load in isolated Electrophysiological effect of volume load in iso

30 Taggart P, Sutton PMI, Treasure T, et al. Contraction/ excitation feedback in man? [abstract]. Br Heart J 1988; 59:109.

31 Taggart $\mathrm{P}$, Sutton PMI, Treasure $\mathrm{T}$, et al. Monophasic action potentials at discontinuation of cardiopulmonary bypass: evidence for contraction-excitation feedback in man. Circulation 1988;77:1266-75.

32 Levine JH, Guarnieri T, Kadish AH, White RI, Calkins H, Kan JS. Changes in myocardial repolarization in patients undergoing balloon valvuloplasty for congenita pulmonary stenosis: evidence for contraction-excitation pulmonary in humans. Circulation 1988;77:70-7.

33 Booth RW, Ryan JM, Mellet HC, Swiss E, Neth E. Hemodynamic changes associated with the Valsalva 1962;59:275-85.

34 Korner PI, Tonkin AM, Uther JB. Reflex and mechanical circulatory effects of graded Valsalva maneuvers in normal man. J Appl Physiol 1976;40:434-40.

35 Smith SA, Salih MM, Littler WA. Assessment of beat to beat changes in cardiac output during the Valsalva manoeuvre using electrical bioimpedance cardiography. Clin Sci 1987;72:423-8.

36 Hoffman BF, Cranefield PF, Lepeschkin E, Surawicz B, Herrlich HC. Comparison of cardiac monophasic potentials recorded by intracellular and suction electrodes. Am J Physiol 1959;196:1297-301.

37 Franz MR BurkhoffD, Spurgeon $H$, Weisfeldt ML, Lakatta EG. In vitro validation of a new cardiac catheter technique for recording monophasic action potentials. Eur Heart $J$ 1986;7:34-41.

38 Herman MV, Heinle RA, Klein MD, et al. Localized disorders in myocardial contraction. Asynergy and its role in congestive heart failure. N Engl J Med 1967;222-32.

39 Herman MV, Gorlin R. Implications of left ventricular asynergy. Am J Cardiol 1969;23:538-47.

40 Leighton RF, Wilt SM, Lewis RP. Detection of hypokinesis by a quantitative analysis of left ventricular cineangiograms. Circulation 1974;50:121-7.

41 Autenrieth G, Surawicz B, Kuo CS. Sequence of repolarization of the ventricular surface in the dog. Am Heart $J$ $197 ;$; $89: 463-9$.

42 Endresen K, Amlie JP, Forfang K, Simonsen S, Jensen O. Monophasic action potentials in patients with coronary artery disease: reproducibility of electrical restitution and of conduction at differ

43 Reuter $\mathrm{H}$. Localization of beta adrenergic receptors, and effects of noradrenaline and cyclic nucleotides on action potentials, ionic currents and tension in mammalian cardiac muscle. J Physiol (Lond) 1974;242:429-51.

44 Autenrieth G, Surawicz B, Kuo CS, Arita M. Primary T wave abnormalities caused by uniform and regional whortening of ventricular monophasic action potential in dog. Circulation 1975;51:668-76.

45 Taggart $P$, Sutton $P$, Lab M, Dean J, Harrison F. Interplay between adrenaline and interbeat interval on ventricular repolarisation in intact heart in vivo. Cardiovasc Res 1990;24:884-95.

46 Butrous GS, Butrous MS, Camm AJ. Dynamic interactions between heart rate and autonomic neural activities on the QT interval. In: Butrous GS, Schwartz PJ eds. Clinical aspects of ventricular repolarization. London: Farrand Press, 1989:139-50.

47 Janse MJ, Wit AL. Electrophysiological mechanisms of ventricular arrhythmias resulting from myocardial ischemia and infarction. Physiol Rev 1989;69:1049-169.

48 El-Sherif N, Gough W. Bradycardia-dependent early after depolarization and triggered activity. A mechanism for the arrhythmogenic effect of some drugs. In: Butrous GS, Schwartz PJ, eds. Clinical aspects of ventricular repolarization. London: Farrand Press, 1989:279-88.

$49 \mathrm{Lab}$ MJ, Dick DJ. Interval dependence of mechanically induced early afterdepolarisations in ventricle of anaesthetised pigs. J Physiol (Lond) (in press).

50 Allessie MA, Bonke FIM, Schopman FJG. Circus movement in rabbit atrial muscle as a mechanism of movement in rabbit atrial muscle as a mechanism of excitability in the occurrence of unidirectional block, as excitability in the occurrence of unidirectional bes 1976; 39:168-77.

51 Gough WB, Mehra R, Restivo M, Zeiler RH, El-Sherif N. Reentrant ventricular arrhythmias in the late myocardial infarction period in the dog: correlation of

52 Olsson SB. Class III antiarrhythmic action. In: Vaughan Williams EM, ed. Handbook of experimental pharmacology. Berlin Springer Verlag, 1989:323-34

53 Taggart P, Sutton PM, John RM, Horner S, Lab MJ, Swanton RH. Influence of ventricular loading and cycle length on ventricular repolarization in humans. Circulation 1990;82 (suppl III):55.

54 Schaper J, Schaper W. Ultrastructural correlates of reduced cardiac function in human heart disease. Eur Heart $J$ 1983;4 (suppl A):35-42.

55 Francis GS. Neurohumoral mechanisms involved in congestive heart failure. Am J Cardiol 1985;55:15A-21A.

56 Stewart DE, Ikram H, Espiner EA, Nicholls MG. Arrhythmogenic potential of diuretic induced hypoheart disease. Br Heart J 1985;54:290-7.

57 Doherty JD, Cobbe SM. Electrophysiological changes in animal model of chronic cardiac failure. Cardiovasc Res 1990;24:309-16.

58 Dean JW, Lab MJ. Arrhythmia in heart failure: the role of mechanically induced changes in electrophysiology. Lancet 1989; i: 1309-12.

59 Dean JW, Lab MJ. Effect of changes in load on monophasic action potential and segment length of pig heart in situ. Cardiovasc Res 1989;23:887-96. 